\title{
Evaluation of LGI1-antibody Encephalitis, a Rare Cause of Limbic Encephalitis, from Diagnosis to Treatment
}

\author{
Limbik Ensefalitin Nadir Bir Nedeni Olan LGI1-antikor Ensefalitinin Tanıdan Tedaviye \\ Kadar Değerlendirilmesi
}

(1) Halil İbrahim Uslusoy, () Yasemin Dinç, () Aylin Bican Demir Bursa Uludag University Faculty of Medicine, Department of Neurology, Bursa, Turkey

Keywords: LGI1-antibody encephalitis, diagnosis, treatment Anahtar Kelimeler: LGI1-antikor ensefaliti, prognoz, tedavi

Dear Editor,

Anti-leucine-rich glioma inactivated-1 (LGI1)-associated limbic encephalitis is a rare neurological disease presenting with subacute progressive encephalopathy and fasciobrachial dystonic seizures (FBDS) (1). LGI1-associated limbic encephalitis is characterized by a poor prognosis, although focal-onset epileptic seizures and cognitive impairment often respond to immunotherapy (2). The prevalence of autoimmune encephalitis is $13 / 100000$, and the incidence rate is 1.2/100000 (3). A case of LGI1-related autoimmune encephalitis responding to immunotherapy with subacute onset cognitive impairment and seizures resistant to antiepileptic therapy was planned to be discussed in the light of the literature. A 67-year-old female patient was admitted to the neurology service for further examination and treatment due to complaints of worsening episodic memory, disorientation, apathy in the last few weeks, aimless wandering around the house and startle on the right side in the last 3 months. After she was hospitalized, it was observed that she had difficulty in fulfilling two-step orders. In the mini-mental state examination, the patient scored 21/30. Serum sodium level was $128 \mathrm{meq} / \mathrm{ml}$, which recovered spontaneously without treatment. In her clinical follow-up, fasciobrachial dystonic seizures were observed. They occured many times during the day, lasting for 10 seconds, accompanied by a clonic beat on the right side of the face, in which the head turned to the right, awareness was preserved, and dystonic posture on the right arm was observed. Interictal wakefulness electroencephalography revealed left frontotemporal weighted $5-6 \mathrm{~Hz} 100-110 \mu \mathrm{V}$ sharp wave activity together with left frontocentrotemporal $6-7 \mathrm{~Hz} 40$ $45 \mu \mathrm{V}$ theta activity (Figure 1). Levetiracetam $1000 \mathrm{mg} /$ day was started and the dose was gradually increased to $3000 \mathrm{mg} /$ day. In the cranial magnetic resonance imaging (MRI) of the patient, on

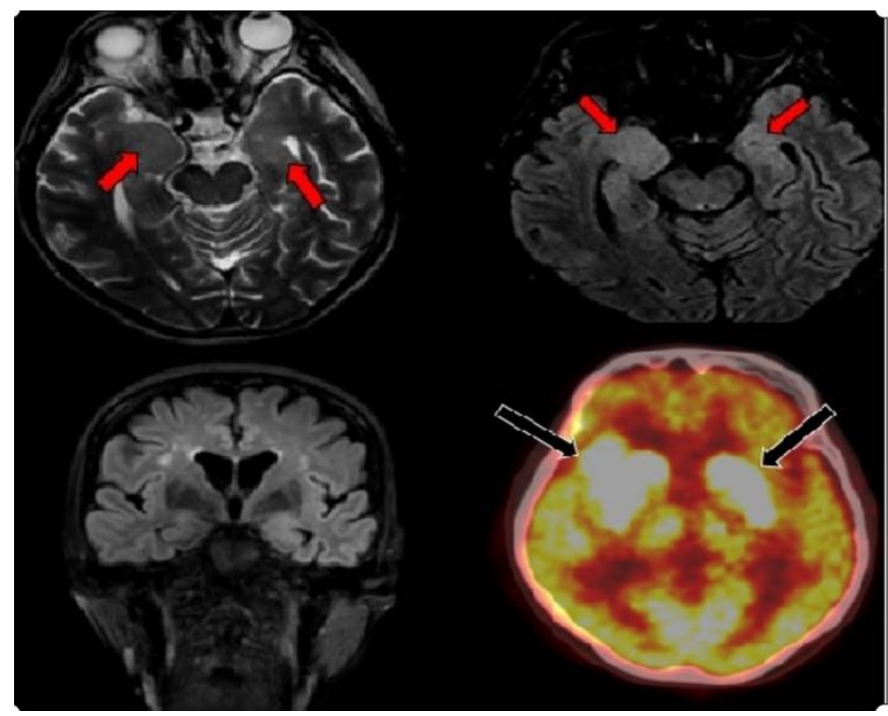

Figure 1. In the cranial MRI, T2W hyperintense bilateral mesial temporal lesions are seen. On the brain PET, bilateral hypermetabolism in the basal ganglia are seen

MRI: Magnetic resonance imaging, PET: Positron emission tomography

Address for Correspondence/Yazışma Adresi: Assoc. Prof. Aylin Bican Demir MD, Bursa Uludag University Faculty of Medicine, Department of Neurology, Bursa, Turkey

Phone: +90 2242951570 E-mail: aylinbican@mynet.com ORCID: orcid.org/0000-0001-6739-8605 Received/Geliş Tarihi: 27.12.2021 Accepted/Kabul Tarihi: 26.02.2022

${ }^{\oplus}$ Copyright 2022 by Turkish Neurological Society

Turkish Journal of Neurology published by Galenos Publishing House. 


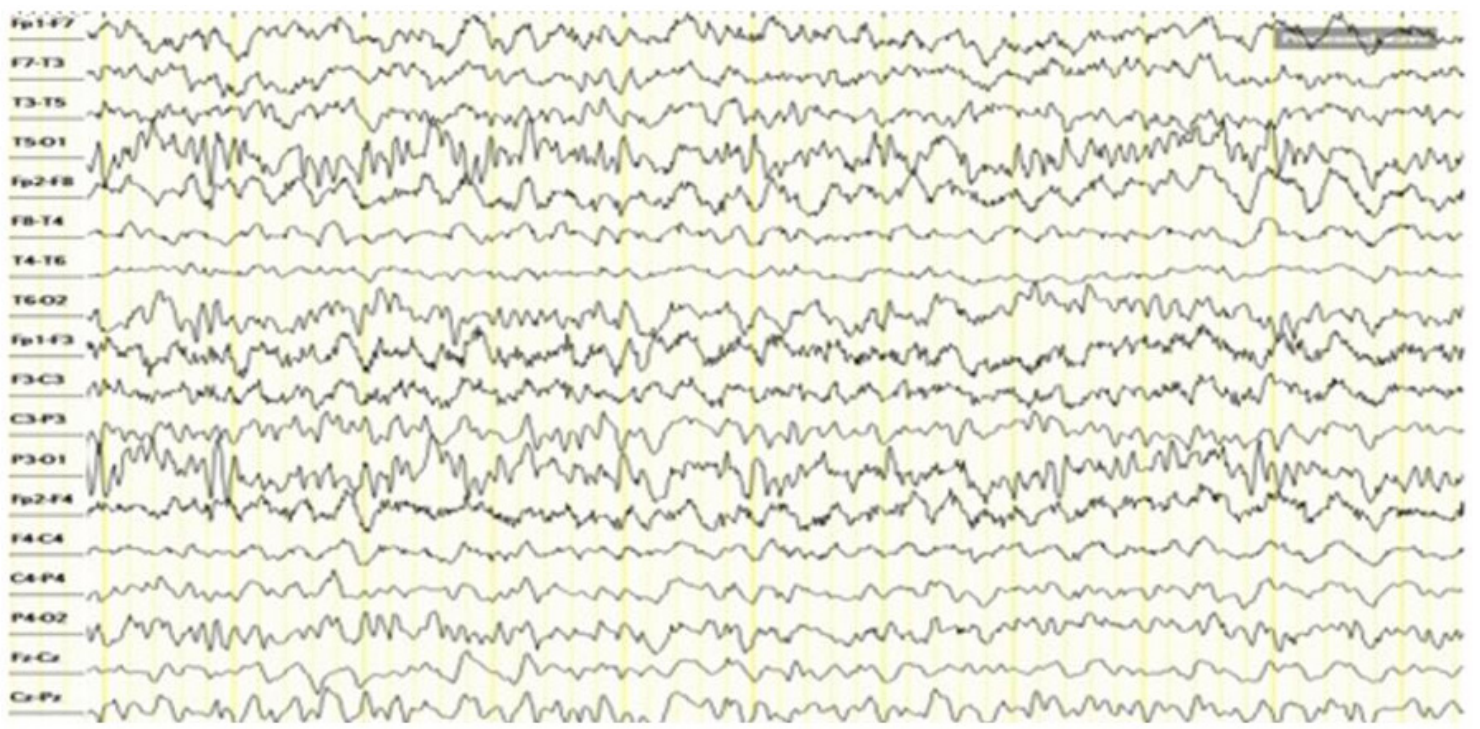

Figure 2. Interictal wakefulness electroencephalography shows left frontotemporal sharp wave activity together with left frontocentrotemporal theta activity

T2W and FLAIR sequences, there were hyperintensities in bilateral mesial temporal lobes (Figure 2). Glucose and protein levels, and cell counts were normal in the cerebrospinal fluid. As the patient's seizures continued, lacosamide $100 \mathrm{mg} /$ day was started and the dose was increased to $400 \mathrm{mg} /$ day due to ongoing seizures. Among the serological markers studied in serum sample, anti-LGI1 was seropositive. Thorax computed tomography (CT), abdominal CT, and whole-body positron emission tomography (PET) did not show any malignancy. On the brain PET, bilateral hypermetabolism was observed in the basal ganglia (Figure 2). Intravenous immune globulin (IVIG) was started at a dose of $2 \mathrm{~g} / \mathrm{kg}$ for 5 days, it was observed that FBDS decreased in the first week after treatment, but there was no significant improvement in cognition. Serum sodium level recovered spontaneously. In the first month after discharge, $1000 \mathrm{mg} /$ day IV methylprednisolone treatment was administered due to sleepiness and frequent seizures. In the first month follow-up, her seizures had disappeared completely, but the patient was still describing episodic memory problems. The patient was treated with $0.5 \mathrm{~g} / \mathrm{kg}$ IVIG per month and she was stable in the first year. In our patient, limbic encephalitis was suspected due to hyperintensity in the bilateral hippocampal structures in T2W and FLAIR sequences in cranial MRI in a patient with subacute onset dementia and focal onset epileptic seizures. For LGI1-related autoimmune encephalitis, it can be said that FDBSs are typical with subclinical seizures. These seizures can repeat many times during the day, lasting for a few seconds, with dystonia, spasm, and contractions involving the ipsilateral face in which awareness is affected or preserved. Ictal extremity dystonia indicates involvement at the level of the basal ganglia, amnesia with ipsilateral automatism indicates involvement in the temporal region, and the forced and involuntary turning of the trunk and head (versive seizure) indicates involvement in the frontal region (4). LGI-1-associated encephalitis often presents with resistance to antiepileptic drug therapy. It exhibits a dramatic response to immunotherapy and corticosteroids. Currently the optimal duration of immunotherapy is not known. In animal studies, LGI1 was found to be highly expressed in the hypothalamus and kidney tubules, so it was assumed that the resistant hyponatremia seen in LGI1-related autoimmune encephalitis was a result of autoimmune mechanisms in the hypothalamic-pituitary axis (5). Its association with malignancy is rare in the literature and it is emphasized that malignancy should be excluded. LGI1 encephalitis should be kept in mind in patients with rapidly progressive cognitive impairment with an age peak between 61-64 years of age.

\section{Ethics}

Informed Consent: Informed consent was obtained from the patient.

Peer-review: Externally peer-reviewed.

\section{Authorship Contributions}

Surgical and Medical Practices: H.İ.U., Y.D., A.B.D., Concept: H.İ.U., Y.D., A.B.D., Design: H.İ.U., Y.D., A.B.D., Data Collection or Processing: H.İ.U., Y.D., A.B.D., Analysis or Interpretation: H.İ.U., Y.D., A.B.D., Literature Search: H.İ.U., Y.D., A.B.D., Writing: H.İ.U., Y.D., A.B.D.

Conflict of Interest: No conflict of interest was declared by the authors.

Financial Disclosure: The authors declared that this study received no financial support.

\section{References}

1. Lancaster E, Dalmau J. Neuronal autoantigens--pathogenesis, associated disorders and antibody testing. Nat Rev Neurol 2012;8:380-390.

2. van Sonderen A, Thijs RD, Coenders EC, et al. Anti-LGI1 encephalitis: clinical syndrome and long-term follow-up. Neurology 2016;87:14491456.

3. Dubey D, Pittock SJ, Kelly CR, et al. Autoimmune encephalitis epidemiology and a comparison to infectious encephalitis. Ann Neurol 2018;83:166-177.

4. Irani SR, Michell AW, Lang B, et al. Faciobrachial dystonic seizures precede Lgi1 antibody limbic encephalitis. Ann Neurol 2011;69:892-900.

5. McQuillan RF, Bargman JM. Hyponatraemia caused by LGI1-associated limbic encephalitis. NDT Plus 2011;4:424-426. 